\title{
Crack sealing capacity in chloride rich environments of mortars containing different cement substitutes and crystalline admixtures
}

\section{Ruben P.Borg, Estefania Cuenca, Enrico Maria Gastaldo Brac and Liberato Ferrara}

\begin{abstract}
This paper presents the results of a preliminary study aimed at assessing the crack sealing capacity in chloride environments of different concrete mixtures, incorporating supplementary cementitious materials as well as self healing enhancing crystalline admixtures. For each addition, also including pulverized fuel ash and silica fume, different contents were taken into consideration.

Cylinder specimens were pre-cracked in splitting up to three different crack opening ranges, simulating different service conditions, and then exposed to different conditioning environments, also containing different concentrations of sodium chloride and including both permanent immersion and wet/dry cycles. Healing conditioning was performed up to three months and crack sealing was visually inspected, and quantified via image analysis procedures, monthly.

Optimum dosages of each cement substitute/addition were quantified, also considering, besides the healing capacity, also the fresh state performance and compressive strength development.

The good performance of mixes with crystalline admixture even under open air exposure, as well as of other investigated mixes as above with reference to crack openings and exposure conditions, paves the way to revise the significance of a serviceability design parameter such as the maximum allowable crack width as a function of the exposure with the concept of a sealable crack width.
\end{abstract}




\section{Introduction}

Reinforced concrete (r/c) structures under marine and chemical attack exposures (XS and XA) experience several durability time-dependent problems, such as ageing and corrosion, needing early and often continuous repair actions. A case history analysis provided by the CON-REP-NET project, showed that $50 \%$ of the repaired concrete structures failed once again, $25 \%$ of which in the first 5 years, $75 \%$ within 10 years and $95 \%$ within 25 years. This is just an example of the urgent need of a profound rethinking of the concept and design processes for new and repaired R/C structures in aggressive environments in view of cost-effectiveness demands.

Moreover, a clear quantitative evaluation of the structure lifespan or service life is so far also lacking. In current design approaches, lifespan is defined by a target reference value, which, through a "structural class concept" and as a function of the exposure class, results into prescriptions deemed to guarantee the demanded level of durability. These prescriptions imply the use of high cement content, low water/cement ratios, suitable aggregates, high reinforcement covers, and the use either conventional or new types of corrosion resistant reinforcement (e.g. stainless/galvanised steel or polymer bars). All what above said results into a non-economic and non-optimal structural design, since the overall member dimensions and the material structural efficiency are impaired by the high cover thickness.

In this context, the availability of self-healing technologies, by controlling and repairing "early-stage cracks in concrete structures, where possible", could, on the one, hand prevent "permeation of driving factors for deterioration", thus extending the structure service life, and, on the other hand, even provide partial recovery of engineering properties relevant to the application.

The ability of concrete and cement based materials, as well as of other hydraulic binders such as limes, to self-seal cracks has been "heuristically" observed for about two centuries (Ferrara et al., 2014).

The aforementioned capacity, depending on the age and width of crack as well as on a significant, if not continuous, presence of water, was regarded as a sort of bonus, able to counteract, in case, the drawbacks of early age shrinkage cracking in certain types of structures, such as tanks and reservoirs, evidently experiencing favourable conditions of exposure.

Though more systematic studies were carried out all along the second half of the last century (Mihashi and Nishiwaki, 2012; van Tittelboom and De Belie, 2013; Snoeck and de Belie, 2015; Ferrara et al., 2016a, 2017; Cuenca and Ferrara, 2017), the topic has been gaining strong and continuously increasing interest in this last decade. This is due, on the one hand, to the dramatic importance that not only the durability of existing concrete structures is being acquiring, not only in the scientific and technical community but also with reference to the awareness and sensitivity of the public opinion. 
On the other hand, the interest in self-healing cement based construction material is steered by the sustainability commitment that the surging demand of buildings, structures and infrastructures is requiring worldwide to the civil engineering sector and to the construction industry.

It is well known that, among all environmental conditions, concentrated chloride exposures such as marine environments are one of the most severe and aggressive (Li, 2011; Tsinker, 1995) since sea water consists mainly of chlorides and sulphates (Maes, 2014a). So far, the vast majority of the studies on permeability of healed concrete cracks are focused on fresh water such as Edvarsen et al. (1999), Yang et al. (2009), Aldea et al. (2000) and Roig-Flores et al. (2015, 2016) among others. However, only very few studies are focused on the crack healing of marine exposed concrete (Li, 2011; Maes, 2014a; Maes, 2014b; Palin, 2015; Maes, 2016; Darquennes, 2016; Palin, 2016; Van Belleghem, 2017).

The autogenous healing could reduce the chloride entry through cracks. Some studies have addressed this aspect: Jacobsen (1996) observed that the rate of chloride migration in the self-healed concretes immersed in water for 3 months was reduced by $28-35 \%$, and penetration time increased compared to newly cracked concretes. Sahmaran (2007) found a significant amount of self-healing within the small cracks (cracks width less than $50 \mu \mathrm{m}$ ) of mortar specimens after 30 days $\mathrm{NaCl}$ solution exposure. The formation of healing products inside the concrete cracks slowed the transportation process of chlorides, this is decreasing the rate of chloride penetration and reducing the effective diffusion coefficient of cracked mortar specimens. Ismail (2008) ensured that self-healing in mortars can prevent the chloride diffusion along a crack. For crack widths greater than $60 \mu \mathrm{m}$ the age of precracking does not affect to the ability of self-healing to prevent chloride diffusion. On the contrary, for cracks smaller than $60 \mu \mathrm{m}$ the age of precracking has a significant effect. Li (2011) observed that microcracks of engineered cementitious composites (ECC), immersed in a $3 \% \mathrm{NaCl}$ solution for 30 days or more, appeared totally sealed as a result of self-healing. These findings confirmed that also microcracked ECC specimens remain durable despite severe marine environment exposures. Maes (2014b) found that crack widths of $100 \mu \mathrm{m}$ and $300 \mu \mathrm{m}$ were autonomous healed for chloride penetration in $67 \%$ and $33 \%$ of the cases, respectively. Palin (2016) found that bacteria-based bead has a great potential for the development of self-healing concrete in low-temperature marine environments. Savija (2016) found that cracks smaller than $60 \mu \mathrm{m}$ have fully recovered their resistance to chloride ingress (full crack healing), however wider cracks only have partially recovered their capacity to resist chloride ingress. Darquennes (2016) observed that blast-furnace slag cementitious materials are often used in concrete structures exposed to coastal and marine environments due to their good chloride penetration resistance. Maes (2016) showed that cracks on cementitious mortars exposed to marine environments are able to be healed and stabilize chloride penetration up to $100 \mu \mathrm{m}$. 
Besides, $10 \mu \mathrm{m}$ is the maximum crack width for chloride penetration. Crack widths smaller than $10 \mu \mathrm{m}$ do not allow chloride penetration along the crack path. Dong (2017) showed that the chloride diffusion coefficient decreased from 8.15 to 6.53 (x 10-12 m2 s-1) after 28-day healing. The healing efficiency of permeability reached a maximum rate equal to $19.8 \%$. Ling (2017) showed that the microbial self-healing cracks can prevent the entrance of chlorides through cracks having a protecting effect for reinforcements in concrete. Van Belleghem (2017) found that the use of self-healing concrete can reduce the chloride concentration in a cracked zone by at least $75 \%$. Finally, it is worth mentioning that all tests and methods used to evaluate durability of concrete and self-healing recovery, such as rapid chloride permeability test and electrical impedance, have been summarized by Cuenca and Ferrara (2017), Muhammad (2016) and Yao (2017).

Focusing in a sustainable design, it is also necessary to pay particular attention to predict and extend the service life of concrete structures, especially those exposed to marine environments (Van de Heede, 2016a; Van Belleghem, 2017). Since concrete has usually at least some cracks, it would be necessary to take into account a cracked state to properly evaluate the service life in a realistic way. In fact, most design codes, such as Eurocode 2, consider acceptable cracks smaller than $300 \mu \mathrm{m}$ for aggressive environmental conditions. ACI 224R (2001), which is one of the most stringent in terms of maximum allowable crack width, allows a maximum crack width at the tensile face of reinforced concrete structures up to $150 \mu \mathrm{m}$ for exposure conditions of seawater, seawater spray, wetting and drying. Self-healing, as already underlined, can extend the service life of concrete structures due to their ability in creating a protective barrier against the ingress of chlorides. In this respect, research on Service Life Extension using self-healing cementitious composites has been developed recently (Van de Heede, 2016a; Van de Heede, 2016b; Van Belleghem, 2017). The assessment of the possible service life extension with self-healing was carried out by means of chloride diffusion tests with concrete containing fly ash. Several researches have shown that if a part of the cement is replaced by fly ash, the concrete that is obtained present a greater resistance to the penetration of chloride (this is, high chloride binding), which is very beneficial for the durability of concrete (Chalee, 2009; Boga, 2012; Darquennes, 2016; Van den Heede, 2017). In addition, water permeability tests showed a higher healing capacity for mixtures with blast-furnace slag, due to the ongoing hydration inside the cracks (Darquennes, 2016). Van den Heede et al. (2016a) evaluated the service life of concrete using the predictions models for chloride-induced depassivation of embedded reinforced steel. The input for the service life model was obtained from experimental chloride profiles. To do that some experimental tests were performed to determine the chloride surface concentration, the instantaneous reference chloride diffusion coefficient, the ageing exponent and the minimum critical chloride concentration. This allowed a good prediction of the chloride-induced steel depassivation period for 
concrete with $15 \%$ of fly ash: in the uncracked state ( 8 years) and in the cracked state (104 years). Comparing these concretes with a concrete with encapsulated polyurethane, an efficiency of 48-76\% in terms of self-healing was obtained. This could extend the corrosion initiation period to 36-68 years. A concrete structure with encapsulated polyurethane would require less repairs and therefore the environmental impact is $77-88 \%$ less compared to traditional (cracked) concrete. Van Belleghem et al. (2017) observed that a steel reinforced self-healing concrete slab exposed to a marine environment could have a service life of 60-94 years compared to 7 years of traditional cracked concrete by embedding encapsulated polyurethane precursor as autonomous healing mechanism in concrete.

In this paper, the first results are shown of a comprehensive collaborative investigation, undertaken by the authors' research group aimed at assessing the crack sealing capacity of different mortar mixes, when exposed to chloride environments. Besides a reference mortar mix, three other categories of mix-designs were considered, with the purpose of promoting crack self-sealing either via pozzolanic cement substitutes (pulverized fuel ashes and silica fume) or by means of tailored admixtures, known as crystalline admixtures, whose efficacy as self-healing promoters has been already documented with reference to both plain and fibre reinforced concrete mixes (Ferrara et al., 2014, 2016b; Roig Flores et al., 2015, 2016; De Nardi et al., 2017).

For each addition, different contents were taken into consideration the investigation being prodromal to the selection of the best performing mix compositions, also accounting for economic considerations, for the ongoing research.

\section{Experimental programme}

As stated above the effect was studied of different cement substitutes and admixtures on the selfhealing capacity of mortars in chloride rich environments. In detail:

- Pulverized fuel ash, employed as replacement of cement in mass ratios equal to 0.10;

- Silica fume, employed as replacement of cement in mass ratio equal to 0.15 ;

- Crystalline admixtures, employed in percentages equal to $1 \%$ of cement weight.

The mix proportions of the different employed mixes are summarized in Table 1.

It can be observed that the water/powder (w/p) ratio was always kept constant at 0.55 . This was referred to the free added water, which was further corrected for the absorption capacity of the employed fibre aggregates. It is worth remarking that this w/p ratio may look high if referred to the maximum recommended value by current design codes for chloride exposure (0.45 - see EN 19921-1). Anyway, the choice has been motivated in order to reproduce the undesirable but often occurring practice, in several construction sites mainly where shortage of skilled workmanship and technical 
personnel occurs, of adding water, e.g. into the mixing truck just before casting to compensate for workability losses in case of long or delayed hauling.

As for the material:

- Cement type CEM II 42.5 R was employed;

- Pulverized Fuel Ash (PFA) was collected from the old power station in Marsa, Malta, which was run on coal. The PFA is a by-product from the combustion of coal and approximately 50,000 tonnes of PFA were dumped at an unused quarry in Benghajsa, and left there to waste (ref PFA). By this, utilizing such materials would be an eco-friendly solution for such waste, which is a very fine toxic powder and appropriate safety precautions need to be taken when being handled. In this project it was sieved using a 0.32 microns sieve prior to casting since it was covered by a layer of sediments at the quarry.

- $\quad$ Silica Fume (SF): Sikacrete® 950 DP was used, in this case provided by Polidano Brothers.

- Crystalline admixture (CA): the admixture Penetron Admix ${ }^{\circledR}$ provided by Penetron Italia was employed. It consists of a mix of proprietary hydrophilic constituents in a carrier of cement and sand; for a complete description of the product the reader is referred to Ferrara et al. (2014).

- Fine aggregate: a calcium carbonate sand with a maximum diameter of $4 \mathrm{~mm}$ was used. It was obtained from a quarry field quarry in WiedFilep, limits of Naxxar, Malta, provided by Ballut Blocks Ltd. Water absorption tests, performed on different samples, resulted into a quite high absorption value of $10 \%$, which was further confirmed by the supplier, and is due to the geological characteristics of the quarry rock formation.

- Water: tap water from the Malta aqueduct was used.

Cylinder specimens $200 \mathrm{~mm}$ high and with a diameter equal to $100 \mathrm{~mm}$ were casted, to be further cut into two $100 \mathrm{~mm}$ high halves. The specimens were cured for 21 days in a temperature controlled $\left(20^{\circ} \mathrm{C}\right)$ water bath. At the end of the curing period, specimens were pre-cracked, by means of a splitting tensile test, performed in displacement control, and measuring the opening of the diameter crack by means of a cross-wise placed LVDT. Three different values of crack opening were induced: - narrow cracks, in the range of $0.10-0.15 \mathrm{~mm}$, variations being due to the different recovery by different specimens upon removal of the pre-cracking loads;

- average cracks, in the range of 0.2 to $0.3 \mathrm{~mm}$;

- large cracks, wider than $0.3 \mathrm{~mm}$, representing a true structural damage, which, even if avoided in design calculation may occur as well due to unpredicted accidental events.

After pre-cracking the specimens were conditioned in the following six different environments for a duration up to 84 days (about three months):

- exposure to open air in the courtyard of the University of Malta; 
- continuous immersion in distilled water at $20^{\circ} \mathrm{C}$;

- exposure to wet and dry cycles, alternating $12 \mathrm{~h}$ immersion in distilled water and $12 \mathrm{~h}$ drying in lab environment;

- continuous immersion in a chloride solution, with sodium chloride concentration of $33 \mathrm{~g} / \mathrm{litre}$, simulating sea water;

- exposure to wet and dry cycles, alternating $12 \mathrm{~h}$ immersion in a sodium chloride solution at a concentration equal to $33 \mathrm{~g} / \mathrm{litre}$ and $12 \mathrm{~h}$ drying in lab environment;

- exposure to wet and dry cycles, alternating $12 \mathrm{~h}$ immersion in a sodium chloride solution at a concentration equal to $165 \mathrm{~g} / \mathrm{litre}$ and $12 \mathrm{~h}$ drying in lab environment; as experienced in structures where de-icing salts are used.

The crack width in all specimens was measured after the pre-cracking, before starting with the conditioning period, by acquiring a complete panorama of the crack by means of a Dynolite digital microscope. Seven micrographs were taken for each specimen and further assembled to completely cover the whole crack, according to the procedure detailed in Roig Flores et al. (2015). The crack width was measured by means of digital image analysis at seven points along its length and the average length was taken as a reference. The procedure, as from previous experience (see also Ferrara et al., 2016) has ben demonstrated to provide stable and reliable results.

At the end of 21, 56 and 84 days conditioning in the aforesaid environments, crack opening was measured again according to the procedure described above, and, through the measured evolution of the crack width, the sealing of the crack was visually assessed and quantified as described in the forthcoming sections.

For each case three nominally identical specimens were tested.

In addition, for all the employed mortar mixes, the fresh state performance was characterized by means of flow-table tests, employing the mini-slump cone, and the compressive strength development was also characterized at different ages, up to 84 days, on $150 \mathrm{~mm}$ side cubes, cast together with the cylinder ones as above.

\section{Experimental results}

\subsection{Fresh state performance}

In Table 2 the flow table spread diameter of the tested mortars are shown. As expectable, by keeping constant the w/p ratio, the use of PFA and SF results in a flowability reduction, because of the higher fineness, specific surface and water absorption of the employed cement substitutes. Crystalline admixtures more moderately affected the flowability. 


\subsection{Compression strength}

As for the compressive strength and its gain along time, the results, plotted in Figure 1, confirm the well consolidated knowledge about the effects of pozzolanic additions and crystalline admixtures. At 28 days, most of the mortars featured a compressive strength equal to about $25 \mathrm{~N} / \mathrm{mm}^{2}$, which is consistent primarily with reference to the employed water/powder and paste to aggregate ratios.

\subsection{Crack sealing}

In the case of the investigated mixes, the self-sealing capacity can be due either to the pozzolanic activity of the PFA or the silica fume or to the activity of the crystalline admixture. All of them need calcium hydroxide to occur, the latter being produced by the cement hydration reactions.

With such a high water content, most of the hydration of cement can be considered as completed at the time of pre-cracking, set at 21 days as above. On the other hand, pozzolanic and crystalline reactions still may need some time to be completed, which the continuous availability of water under some of the investigated curing conditions may promote. Moreover, the presence of chlorides in sea water may promote some kind of chloride binding reaction, which may also contribute to self-healing, as the results hereafter explained in detail will better illustrate.

\subsubsection{Index of Crack Sealing}

The effectiveness of the crack sealing capacity has been, from the crack width measurements garnered as described above, by calculating for each the investigated experimental situations, the Index of Crack Sealing, defined as follows:

$$
\mathrm{ICS}=1-\frac{w\left(t_{i}\right)}{w_{0}}
$$

where $w\left(t_{i}\right)$ and $w_{0}$ are the crack width at time $i$ (different conditioning times, as above) and immediately after pre-cracking (conditioning time zero).

\subsubsection{Influence of the mix composition - continuous immersion exposure}

The results are plotted in terms of evolution of the crack-sealing index over time, separately for the three different ranges of crack opening widths considered and for the different investigated exposure conditions. As first step the two continuous water immersion conditions, dealing with both distilled water and water containing $33 \mathrm{~g} / \mathrm{l}$ sodium chloride.

With reference to immersion in distilled water, for both small and intermediate crack ranges all mixes achieve, after 84 days and in some cases even earlier, complete closure of the crack (Figure 2a-c; almost complete closure for the reference mix in the case of intermediate crack openings). This can be also observed by crack pattern pictures in Figure 3. The kinetics of the measured crack closure is 
different: while for small crack openings the reference mix and the one with PFA feature the fastest sealing for intermediate crack openings the mix containing crystalline admixtures undergoes the most rapid sealing of the crack. This is consistent with results obtained by Ferrara et al. (2014) for similar crack opening ranges and was explained with larger cracks exposing to water larger quantities of hydrophillic and reactive material. The global effect is hence a synergic combination of the reactivity of the admixture itself with both water and cement hydration products (calcium hydroxide) and of its catalyst action on further hydration of cement. For other mixes, relying either on delayed hydration of cement or on pozzolanic reaction of cement substitutes, larger cracks correspond to slower sealing kinetics. Coherently with this assumption, for large crack widths, the crystalline admixture, despite an initial slower start, features the higher sealing rate at the end of the 84 days observation period.

With the reference to the immersion in sodium chloride solution (Figure 4a-c), it can be first of all observed that, irrespective of the initial crack opening, the kinetics of the sealing is slower; anyway all the mixes achieve complete sealing of small cracks and, except for the reference mix, also for cracks widths with openings in the intermediate range. For larger crack openings, the sealing was both slower and less effective than in distilled water for all the mixes, the one with crystalline admixture still exhibiting the best performance. Interestingly it can be observed that the reference mix, for intermediate crack opening ranges, shows, after an initial quite fast sealing a substantial stop of the phenomenon. It could be reasonably argued that together with the delayed hydration reactions some kind of chloride binding reactions also occurred which anyway quite rapidly saturated the reactivity of the unhydrated cement particles. Similar reasons may hold to justify the similar trend detected for the SF mix for larger cracks, allowing larger penetration of water and hence more prompt onset of the reactions, which anyway also consume quite faster the available reactive constituents. Anyway, random 3D features of a crack, herein represented only through its surface opening (Figures 3 and 5), are also likely to affect pointwise data and hence the aforementioned statements are meaningful as trend indicators.

\subsubsection{Influence of the mix composition - wet and dry cycles exposure}

Exposure to wet and dry cycles, either in distilled water or in sodium chloride solutions with two different salt concentration, reveals further interesting facts which can support the assumption of chloride binding reactions participating to crack sealing.

From the graphs in Figure 6 a-c it clearly appears that the crack sealing performance under wet and dry cycles is always lower than under continuous immersion, the same statements holding as above as far as the effectiveness of the different crack sealing activators is concerned. Interestingly, mix with silica fume continuous to maintain an appreciable crack sealing capacity even for larger cracks 
because of both the high employed amount and of the fineness of its particles able to absorb significant water during the wetting stages of the cycles. Anyway, in no case complete crack sealing is achieved even after three months conditioning.

On the other hand, specimens conditioned under wet and dry cycles in sodium chloride solutions exhibited in most cases complete closure of the crack, even for intermediate openings, upon longer conditioning duration (Figure $7 \mathrm{a}-\mathrm{c}$ ). Moreover, the fact that specimens conditioned in higher concentration solutions exhibited the best crack sealing performance (Figure 8 a-c) may stand as a confirmation of this assumption. Interestingly the mix containing silica fume and the mix with crystalline admixtures showed the best performance, in terms of both kinetics and final efficacy of the sealing.

\subsubsection{Influence of the mix composition-exposure to air}

Mixes with crystalline admixture performed quite well also for exposure to open air, being able to completely seal cracks under $0.15 \mathrm{~mm}$ opening and guaranteeing about $75 \%$ crack sealing capacity even for intermediate crack openings. Interestingly also mixes with other cement substitutes provided good performance for narrow and intermediate crack openings.

Such an outcome is highly interesting in view of guaranteeing the durability not only to structures or parts of a structure completely submerged (exposure class XS1 as per EN 206) or exposed to splash/tidal zone (exposure class XS2 as per EN 206) but also to aerial part of an offshore structure as well as to onshore structures in coastal areas (exposure class XS3 as per EN 206).

\subsubsection{Effects of exposure conditions}

The results analysed above are plotted, for each mix composition and for the different analysed crack openings, as a function of the exposure conditions (Figure $13 \ldots$...)

It clearly appears, for all the mixes and with reference to most of the investigated crack-opening ranges, that besides full water immersion, also exposure to wet and dry cycles in chloride solutions yield good results, the higher the $\mathrm{NaCl}$ content the faster and better the crack sealing. This confirms the educated guess exposed above that, besides typical delayed hydration and/or carbonation reactions which are responsible for autogenous crack sealing, in case enhanced through different additions, also chloride binding is likely to occur, leading to the formation of products which precipitating onto the crack surfaces also contribute to the crack closure. Crystalline admixtures and silica fume, because of their high reactivity, and, to a lesser extent, fly ashes, enhance this reaction. 


\subsubsection{Effects of crack opening}

Same results plotted and commented above can also be analyses to assess the effect of crack opening for the different mixes and exposure conditions. The following statements hold:

- For the reference mix the healing capacity generally decreases with increasing crack width; an exception is represented by exposure to open air and to w/d cycles in distilled water, where the larger crack may probably expose to the moisture/water a larger share of clusters of reactive unhydrated binder particles (or un-carbonated in the case of the drying phases of the w/d cycles).

- The same holds also for the mix containing fly ashes.

- The mixes containing silica fume and crystalline admixture on the other hand feature a significant decrease of the crack sealing capacity only for very large crack widths and/or for conditions where there is lower water availability. Significantly, some mixes with SF and CA feature complete crack closure after 84 days even for cracks up to $0.3 \mathrm{~mm}$ wide under water immersion, both distilled and chloride solution, and for w/d cycles in high $\mathrm{Cl}$ content solution. The mix with crystalline admixture is able to completely seal the cracks also when exposed to w/d cycles in low $\mathrm{Cl}$ content solution and in open air for intermediate crack openings.

\section{Concluding remarks}

In this paper the preliminary results are shown of an investigation aimed at assessing the effectiveness of crack sealing capacity under chloride rich environments of concrete containing different selfhealing facilitators, including pulverized fuel ash, silica fume and crystalline admixtures. Optimum dosages have been first of all determined through preliminary investigation, also considering fresh state performance and compressive strength development. As for the exposure conditions to investigate crack sealing, continuous immersion and wet/dry cycles in $33 \mathrm{~g} / \mathrm{l}$ chloride solution and wet/dry cycles in $165 \mathrm{~g} / 1$ chloride solutions have been considered. For the sake of comparison immersion and wet/dry cycles in distilled water have been also considered, together with exposure to open air. Being a preliminary investigation, crack sealing has been only visually monitored, further work is ongoing to investigate the chemical reactions occurring under the selected conditions.

The following conclusions can be drawn:

- concrete crack sealing capacity under sea water (with reference to both continuous immersion and exposure to wet/dry cycles) is confirmed and may be even better than in distilled water; in several cases the higher the chloride content, the better and faster the healing, most likely because of a synergy effect between sealing reactions (delayed hydration and/or carbonation) and chloride binding; in general the crack sealing capacity decreases with the opening of the crack whereas it continues upon prolonged exposure; 
- reference concrete was able to complete seal narrow cracks under continuous immersion in water and chloride solutions after about three months; complete sealing was also achieved for wet/dry cycles in high concentration saline solutions;

- pulverized fuel ash additions enhance the aforementioned sealing capacity, but up to a replacement ratio not higher than $20 \%$ by weight of cement and only with reference to smaller crack openings and also intermediate ones; effects of exposure conditions is as for reference concrete;

- mixes containing high addition of silica fume, ( $15 \%$ by mass of cement) also enhance the crack sealing capacity under continuous immersion and wet/dry cycles exposure, both in fresh water and chloride solutions and up to intermediate crack opening ranges;

- the high hydrophilic activity of crystalline admixtures makes it able to perform in a very good way under almost all the investigated exposure conditions and even for cracks opened up to $0.3 \mathrm{~mm}$;

- comparable performance to the mixes with crystalline admixtures, but for a few cases, was exhibited by the mix with $15 \%$ silica fume cement replacement. Mix with PFA and reference mix followed in order of performance.

The good performance of mixes with crystalline admixture even under open air exposure, as well as of other investigated mixes as above with reference to crack openings and exposure conditions, paves the way to revise the significance of a serviceability design parameter such as the maximum allowable crack width as a function of the exposure with the concept of a sealable crack width.

This investigation has to be intended as preliminary to pave the way for ongoing research activity, the authors are presently working on, focusing on improving chloride penetration resistance through crack sealing and assessing the outcomes of this on the reinforcement corrosion and decay/recovery of bond strength and behaviour.

\section{References}

ACI Committee 224 (2001) Control of Cracking in Concrete Structures - ACI 224R-01. American Concrete Institute, Farmington Hills, MI, 45 pp.

Aldea C, Song W, Popovics JS, Shah SP (2000) Extent of healing of cracked normal strength concrete. Journal of Materials in Civil Engineering 12: 92-96.

Boga AR, Topçu IB (2012) Influence of fly ash on corrosion resistance and chloride ion permeability of concrete. Construction and Building Materials 31: 258-264.

Chalee W, Jaturapitakkul C, Chindaprasirt P (2009) Predicting the chloride penetration of fly ash concrete in seawater. Marine Structures 22: 341-353. 
Cuenca E, Ferrara L (2017) Self-healing Capacity of Fiber Reinforced Cementitious Composites. State of the Art and Perspectives. KSCE Journal of Civil Engineering 1-13, doi:10.1007/s12205-0170939-5.

Darquennes A, Olivier K, Benboudjema F, Gagné R (2016) Self-healing at early-age, a way to improve the chloride resistance of blast-furnace slag cementitious materials. Construction and Building Materials 113: 1017-1028.

De Nardi, C., Bullo, S., Ferrara, L., Ronchin, L. and Vavasori, A. (2017) “Effectiveness of crystalline admixtures and lime/cement microcapsules in engineered self-healing capacity of lime mortars", Materials and Structures, 50 (4): 191.1-191.12

Dong B, Fang G, Wang Y, Liu Y, Hong S, Zhang J, Lin S, Xing F (2017) Performance recovery concerning the permeability of concrete by means of a microcapsule based self-healing system. Cement and Concrete Composites 78: 84-96.

Dossche C, Boel V, De Corte W, Van den Heede P, De Belie N (2016) A plant based LCA of highstrength prestressed concrete elements and the assessment of a practical ecological variant. Cement and Concrete Composites 73: 192-202.

Edvardsen C (1999) Water permeability and autogenous healing of cracks in concrete. ACI Materials Journal 96(4): 448-454.

Ferrara, L., Krelani, V. and Carsana, M. (2014) A fracture testing based approach to assess crack healing of concrete with and without crystalline admixtures, Construction and Building Materials, 68: 515-531.

Ferrara, L., Krelani, V. and Moretti, F. (2016a) Autogenous healing on the recovery of mechanical performance of High Performance Fibre Reinforced Cementitious Composites (HPFRCCs): part 2 correlation between healing of mechanical performance and crack sealing, Cement and Concrete Composites, 73: 299-.315.

Ferrara, L., Krelani, V. and Moretti, F. (2016b) "On the use of crystalline admixtures in cement based construction materials: from porosity reducers to promoters of self healing”, Smart Materials and Structures, 25: 084002 (17pp) doi:10.1088/0964-1726/25/8/084002.

Ferrara, L., Krelani, V., Moretti, F., Roig Flores, M. and Serna Ros, P. (2017) Effects of autogenous healing on the recovery of mechanical performance of High Performance Fibre Reinforced Cementitious Composites (HPFRCCs): part 1, Cement and Concrete Composites, 83: 76-100.

Ismail M, Toumi A, François R, Gagné R (2008) Effect of crack opening on the local diffusion of chloride in cracked mortar samples. Cement and concrete research 38(8): 1106-1111.

Jacobsen S, Marchand J, Boisvert L (1996) Effect of cracking and healing on chloride transport in OPC concrete. Cement and Concrete Research 26(6): 869-881. 
Li M, Li VC (2011) Cracking and Healing of Engineered Cementitious Composites under Chloride Environment. ACI Materials Journal 108(3): 333-340.

Li VC, Herbert E (2012) Robust Self-Healing Concrete for Sustainable Infrastructure. Journal of Advanced Concrete Technology 10: 207-218.

Ling H, Qian C (2017) Effects of self-healing cracks in bacterial concrete on the transmission of chloride during electromigration. Construction and Building Materials 144: 406-411.

Maes M, De Belie N (2014a) Resistance of concrete and mortar against combined attack of chloride and sodium sulphate. Cement and Concrete Composites 53: 59-72.

Maes M, Snoeck D, De Belie N (2016) Chloride penetration in cracked mortar and the influence of autogenous crack healing. Construction and Building Materials 115: 114-124.

Maes M, Van Tittelboom K, De Belie N (2014b) The efficiency of self-healing cementitious materials by means of encapsulated polyurethane in chloride containing environments. Construction and Building Materials 71: 528-537.

Mihashi, H. and Nishiwaki, T. (2012) Development of engineered self-healing and self-repairing concrete: state-of-the-art report, Journal of Advanced Concrete Technology, 10: 170-184.

Muhammad NZ, Shafaghat A, Keyvanfar A, Majid MZA, Ghoshal SK, Yasouj SEM, Ganiyu AA, Kouchaksaraei MS, Kamyab H, Taheri MM, Shirdar MR, McCaffer R (2016) Test and methods of evaluating the self-healing efficiency of concrete: A review. Construction and Building Materials 112: $1123-1132$.

Pacheco J, Polder R (2012) Corrosion initiation and propagation in cracked concrete-a literature review. In Advances in Modeling Concrete Service Life (pp. 85-93). Springer Netherlands.

Palin D, Wiktor V, Jonkers HM (2015) Autogenous healing of marine exposed concrete: characterization and quantification through visual crack closure. Cement and Concrete Research 73: $17-24$.

Palin D, Wiktor V, Jonkers HM (2016) A bacteria-based bead for possible self-healing marine concrete applications. Smart Materials and Structures 25: 1-6.

Roig-Flores, M., Moscato, S., Serna. P. and Ferrara, L. (2015) Self-healing capability of concrete with crystalline admixtures in different environments, Construction and Building Materials, 86: 1-11. Roig-Flores M, Pirritano F, Serna P, Ferrara L (2016) Effect of crystalline admixtures on the selfhealing capability of early-age concrete studied by means of permeability and crack closing tests. Construction and Building Materials 114: 447-457.

Şahmaran M (2007) Effect of flexure induced transverse crack and self-healing on chloride diffusivity of reinforced mortar. Journal of Materials Science 42(22): 9131-9136.

Savija B, Schlangen E (2016) Autogenous healing and chloride ingress in cracked concrete. HERON 
61(1): 15-32.

Snoeck, D. and De Belie, N., From straw in bricks to modern use of microfibers in cementitious composites for improved autogeneous healing - A review, Construction and Building Materials, 95 (2015), 774-787.

Tsinker G P (1995) Marine Structures Engineering: Specialized Applications, 548 pp.

Van Belleghem B, Van den Heede P, Van Tittelboom K, De Belie N (2017) Quantification of the Service Life Extension and Environmental Benefit of Chloride Exposed Self-Healing Concrete. Materials 10(5): 1-22.

Van den Heede P, De Keersmaecker M, Elia A, Adriaens A, De Belie N (2017) Service life and global warming potential of chloride exposed concrete with high volumes of fly ash. Cement and Concrete Composites 80: 210-223.

Van den Heede P, Van Belleghem B, De Keersmaecker M, Adriaens A, De Belie N (2016a) Sustainability Effects of Including Concrete Cracking and Healing in Service Life Prediction for Marine Environments. In: Fourth International Conference on Sustainable Construction Materials and Technologies SMCT4, Las Vegas, USA.

Van den Heede P, Van Belleghem B, De Belie N (2016b) The cost and environmental impact of service life extending self-healing engineered materials for sustainable steel reinforced concrete. In: Expanding Boundaries: Systems Thinking for the Built Environment. Sustainable Built Environment (SBE) Regional Conference. Zurich.

Van Tittelboom, K. and De Belie, N. (2013) Self-healing in cementitious materials - a review, Materials, 6: 2182-2217.

Yang Y, Lepech MD, Yang EH, Li VC (2009) Autogenous healing of engineered cementitious composites under wet-dry cycles. Cement and Concrete Research 39(5): 382-390.

Yao Y, Wang L, Wittmann FH, De Belie N, Schlangen E, Gehlen C, Wang Z, Egüez-Álava H, Cao Y, Yunus BMD, Li J (2017) Recommendation of RILEM TC 246-TDC: test methods to determine durability of concrete under combined environmental actions and mechanical load. Materials and Structures 50:155. 


\section{Tables}

Table 1. Mix proportions (by mass) for the different investigated mortars

\begin{tabular}{|c|c|c|c|c|}
\hline & A & B & C & D \\
\hline Cement & 1 & 0.80 & 0.85 & 0.99 \\
\hline Water & 0.55 & 0.55 & 0.55 & 0.55 \\
\hline Sand & 3 & 3 & 3 & 3 \\
\hline PFA & & 0.20 & & \\
\hline SF & & & 0.15 & \\
\hline CA & & & & 0.01 \\
\hline
\end{tabular}

Table 2. Flow spread diameters for the different investigated mortars

\begin{tabular}{|c|c|c|}
\hline Mix ID & specification & Flow spread diameter (mm) \\
\hline A & Reference & 227.5 \\
\hline C & $20 \%$ PFA & 190.0 \\
\hline H & $15 \%$ SF & 185.0 \\
\hline J & $1 \%$ CA & 205.0 \\
\hline
\end{tabular}

\section{Figures}

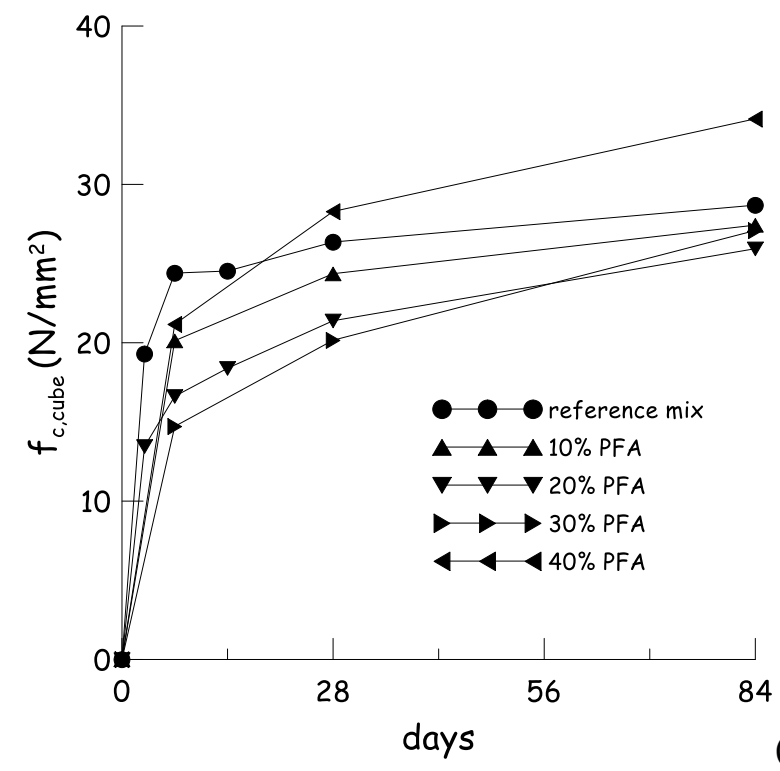

Figure 1: effect on cube compressibe strength of cement replacement with pulverized fuel PFA and silica fume SF and of the addition of crystalline admixture CA. 


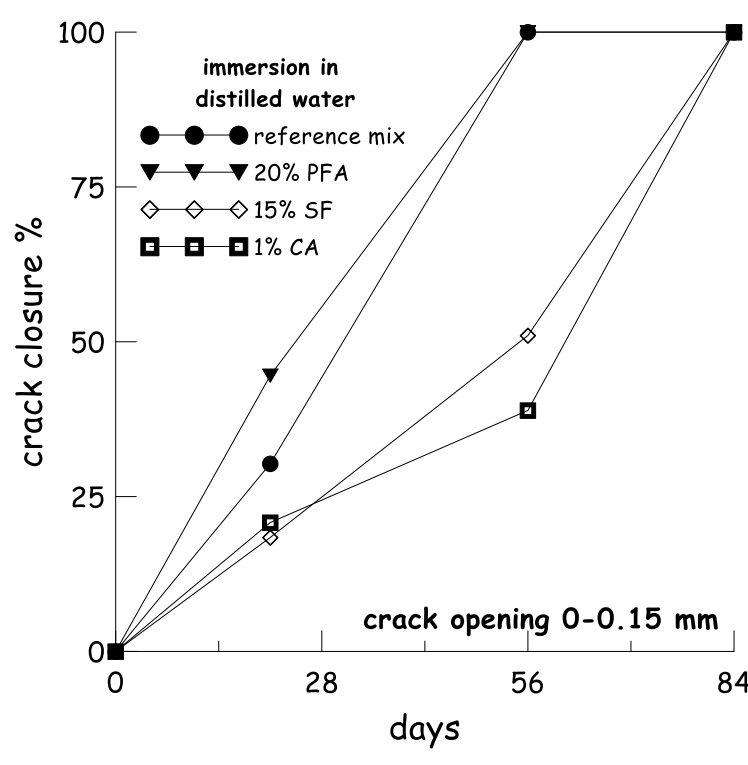

(a)
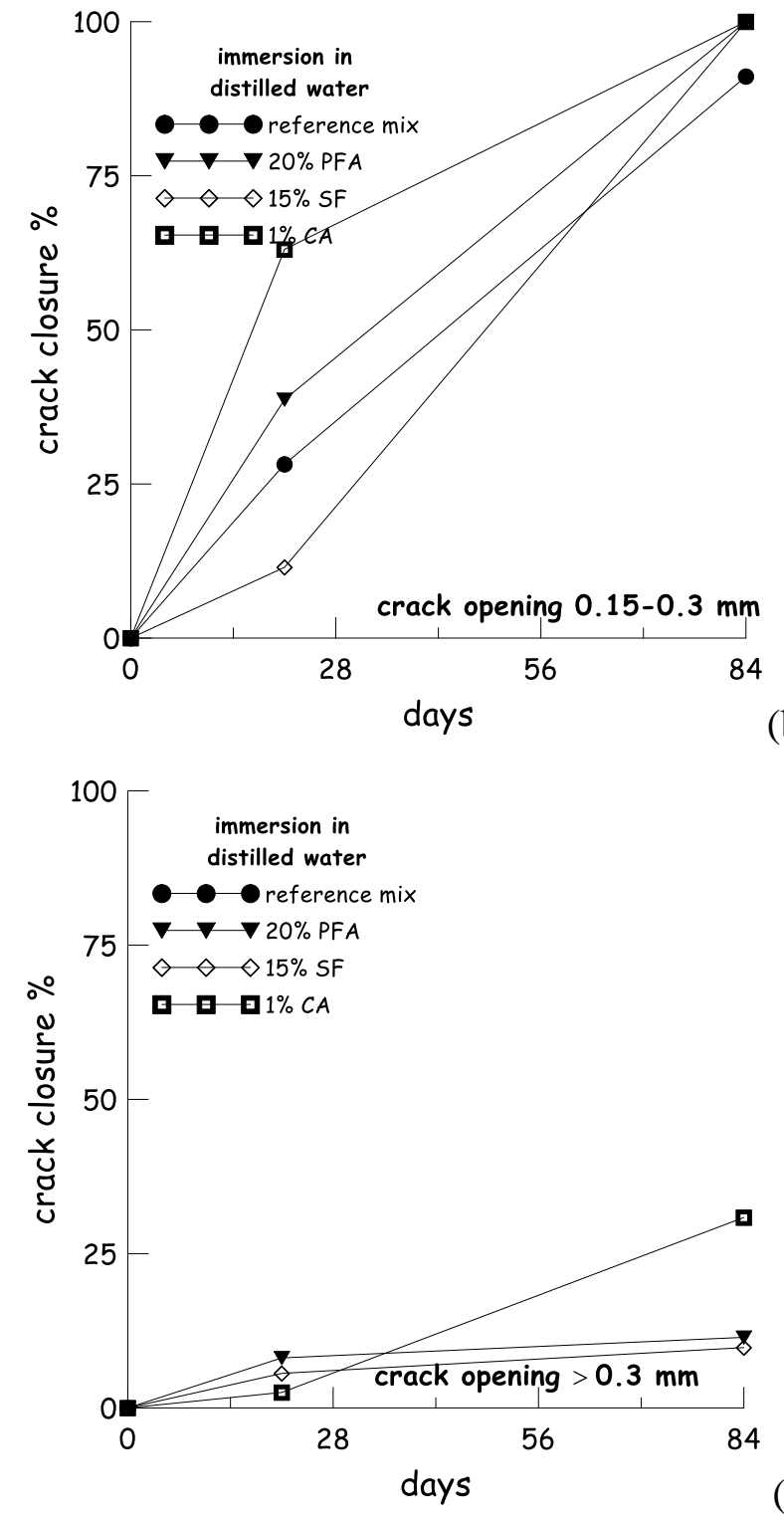

(b)

Figure 2: effects of mix composition on crack sealing under continuous water immersion for narrow (a), intermediate (b) and large (c) crack openings. 


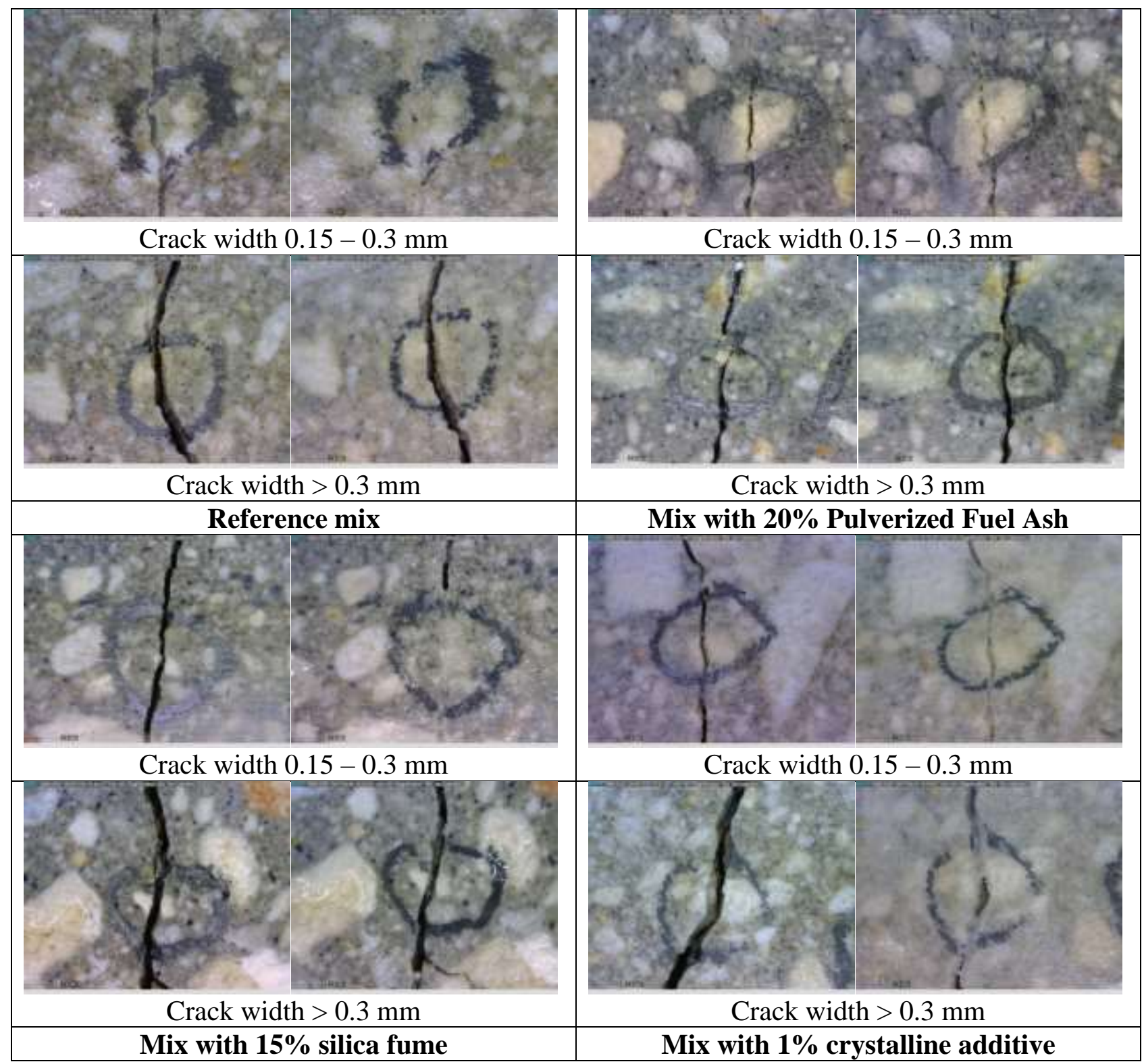

Figure 3: visual images of crack sealing after 3 months of continuous immersion in distilled water. 


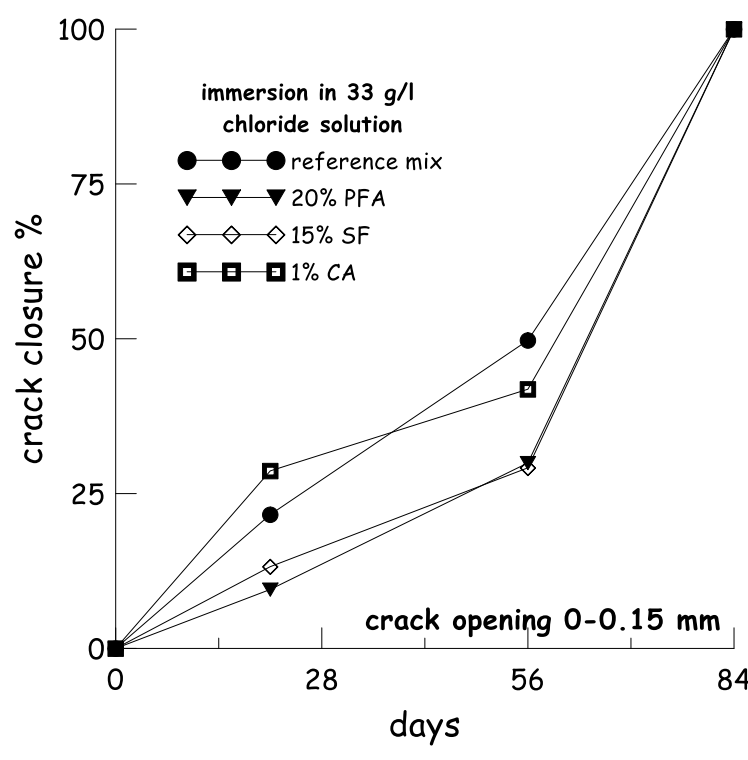

(a)

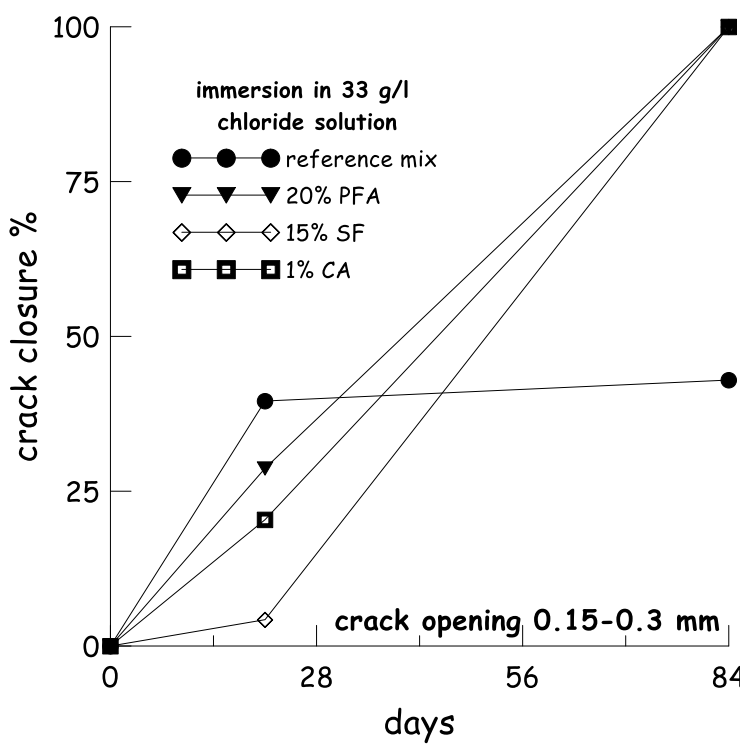

(b)

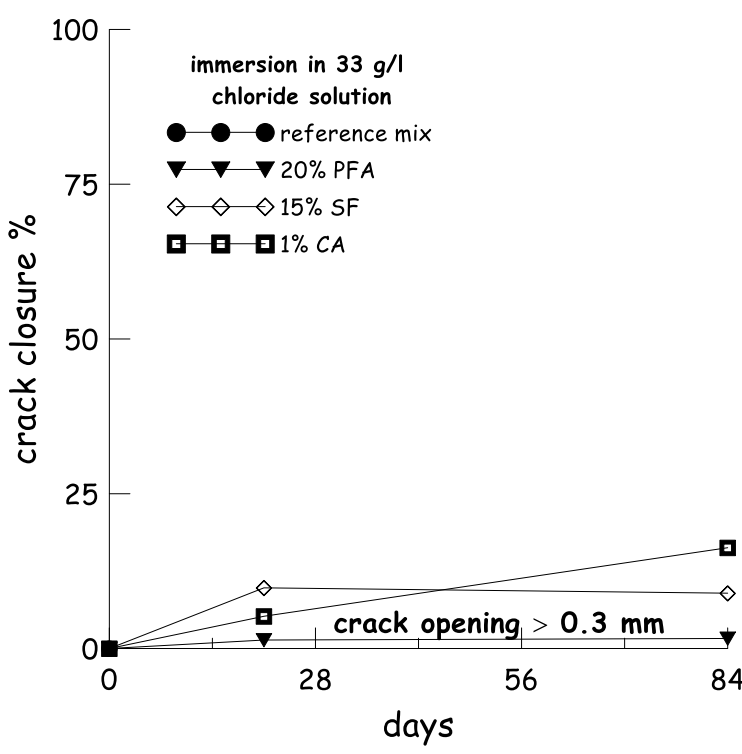

Figure 4: effects of mix composition on crack sealing under continuous immersion in $\mathrm{NaCl}$ solution for narrow (a), intermediate (b) and large (c) crack openings. 


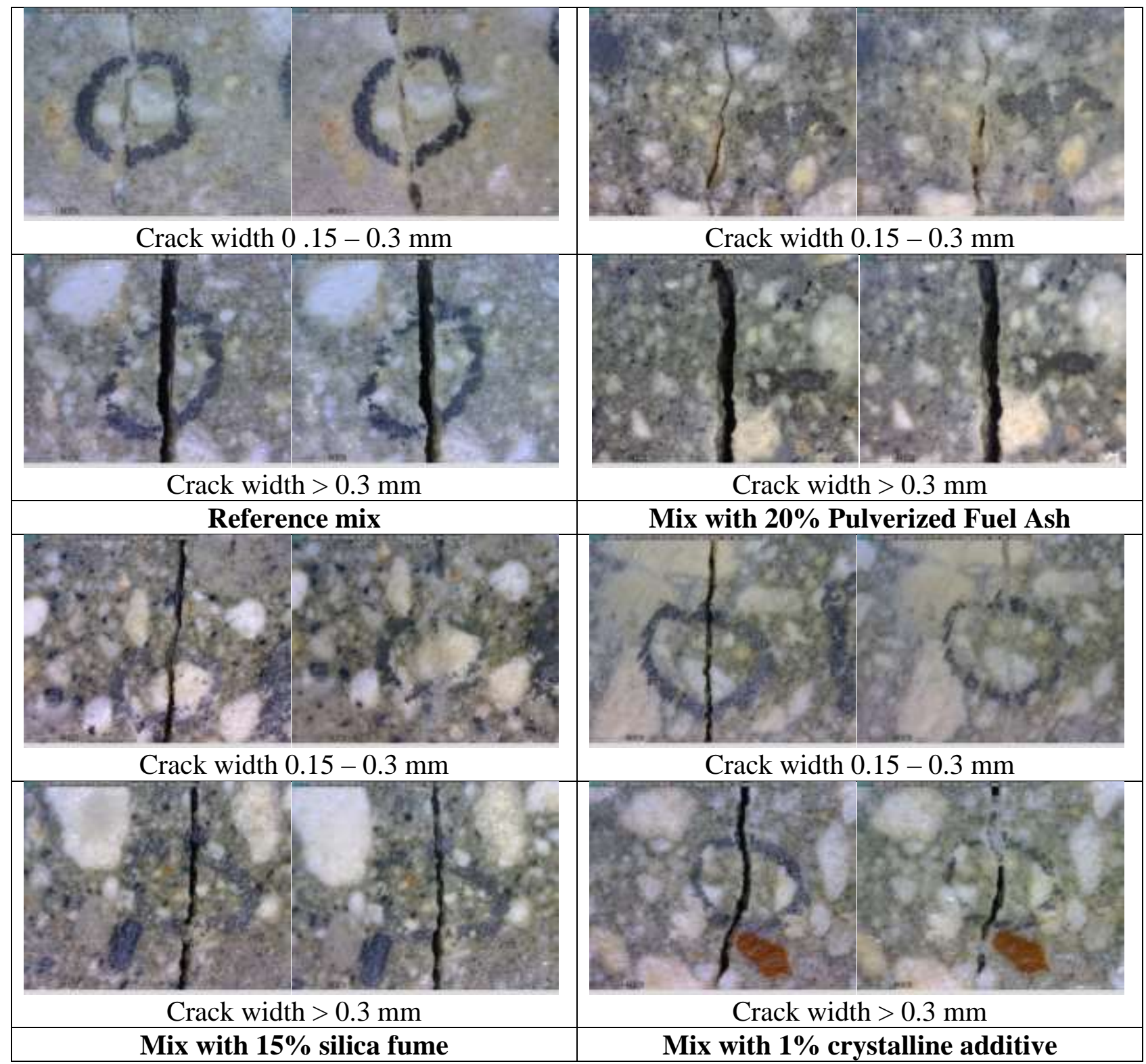

Figure 5: visual images of crack sealing after 3 months of continuous immersion in $33 \mathrm{~g} / \mathrm{l} \mathrm{NaCl}$ solution. 


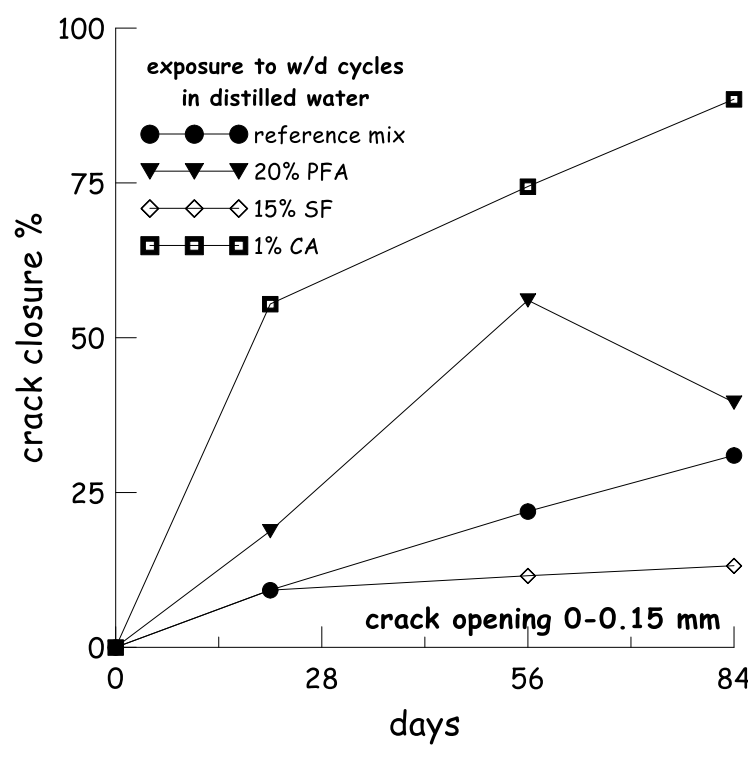

(a)

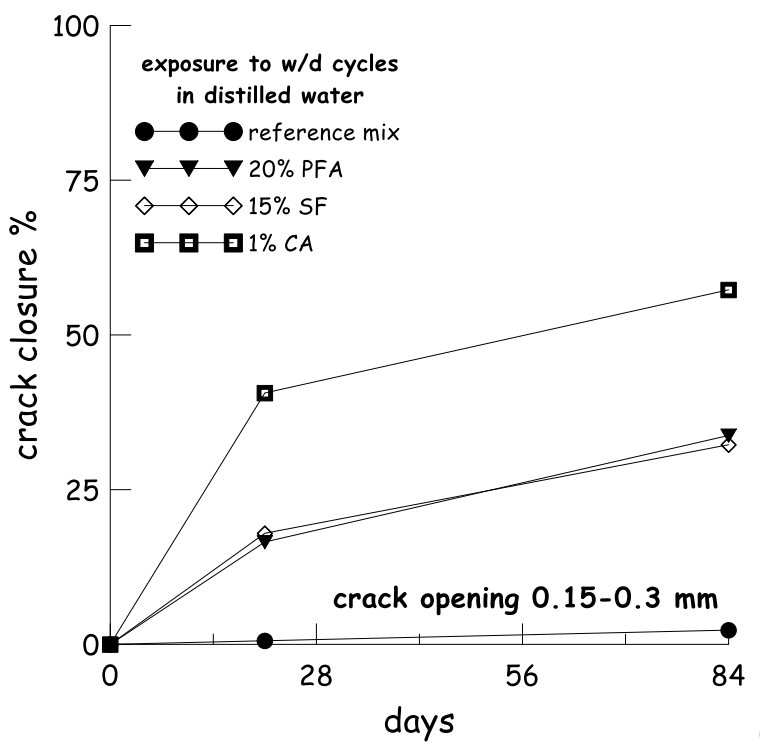

(b)

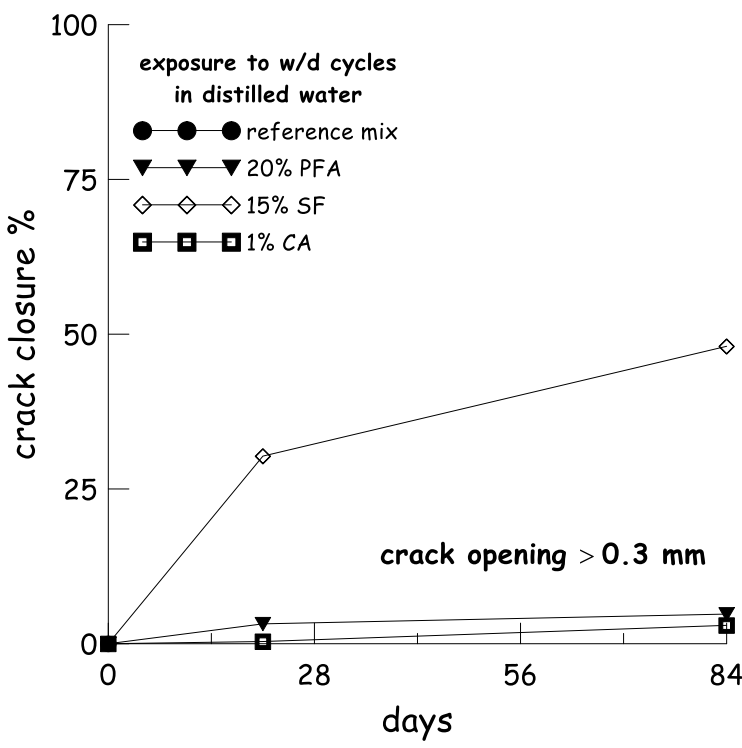

Figure 6: effects of mix composition on crack sealing under wet and dry cycles in distilled water for narrow (a), intermediate (b) and large (c) crack openings. 

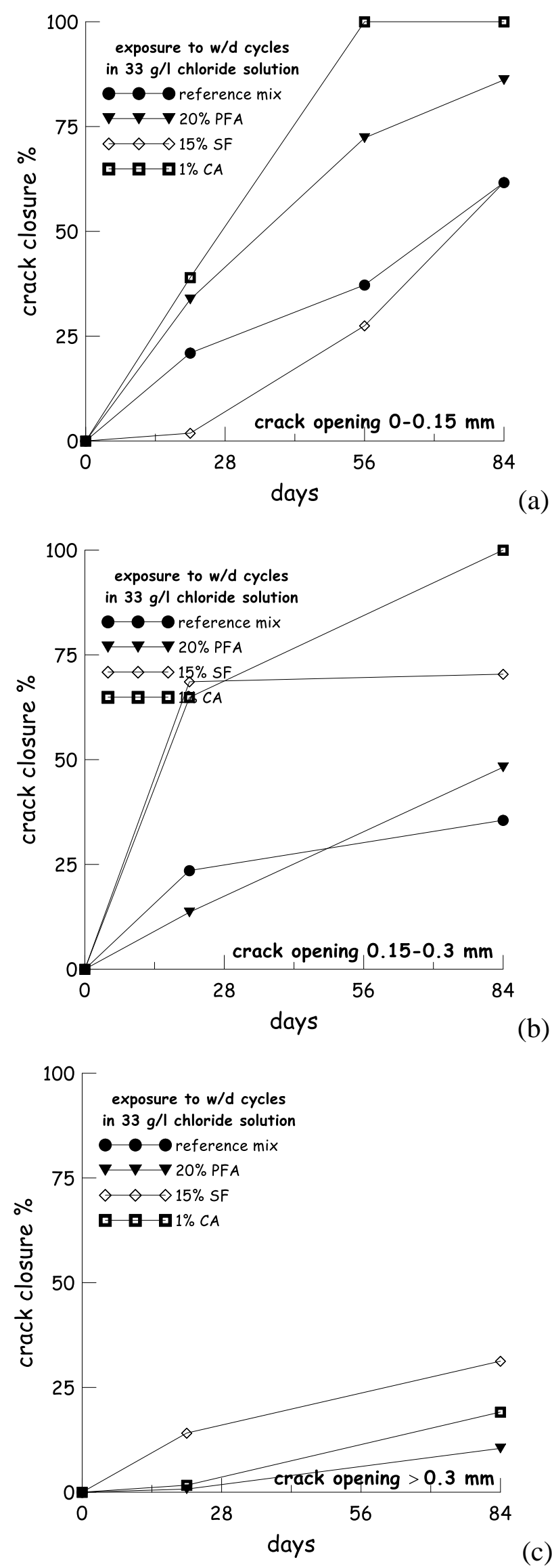

(b)

Figure 7: effects of mix composition on crack sealing under wet and dry cycles in $33 \mathrm{~g} / \mathrm{l}$ sodium chloride solution for narrow (a), intermediate (b) and large (c) crack openings. 

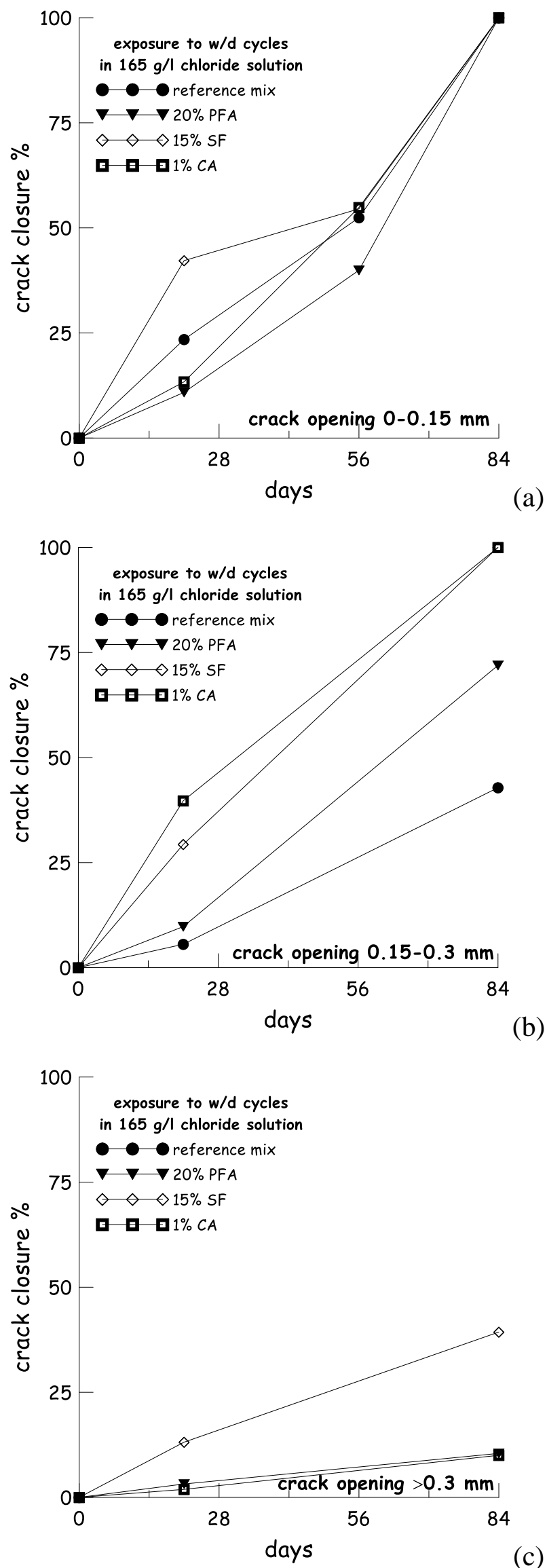

Figure 8: effects of mix composition on crack sealing under wet and dry cycles in $165 \mathrm{~g} / \mathrm{l}$ sodium chloride solution for narrow (a), intermediate (b) and large (c) crack openings. 


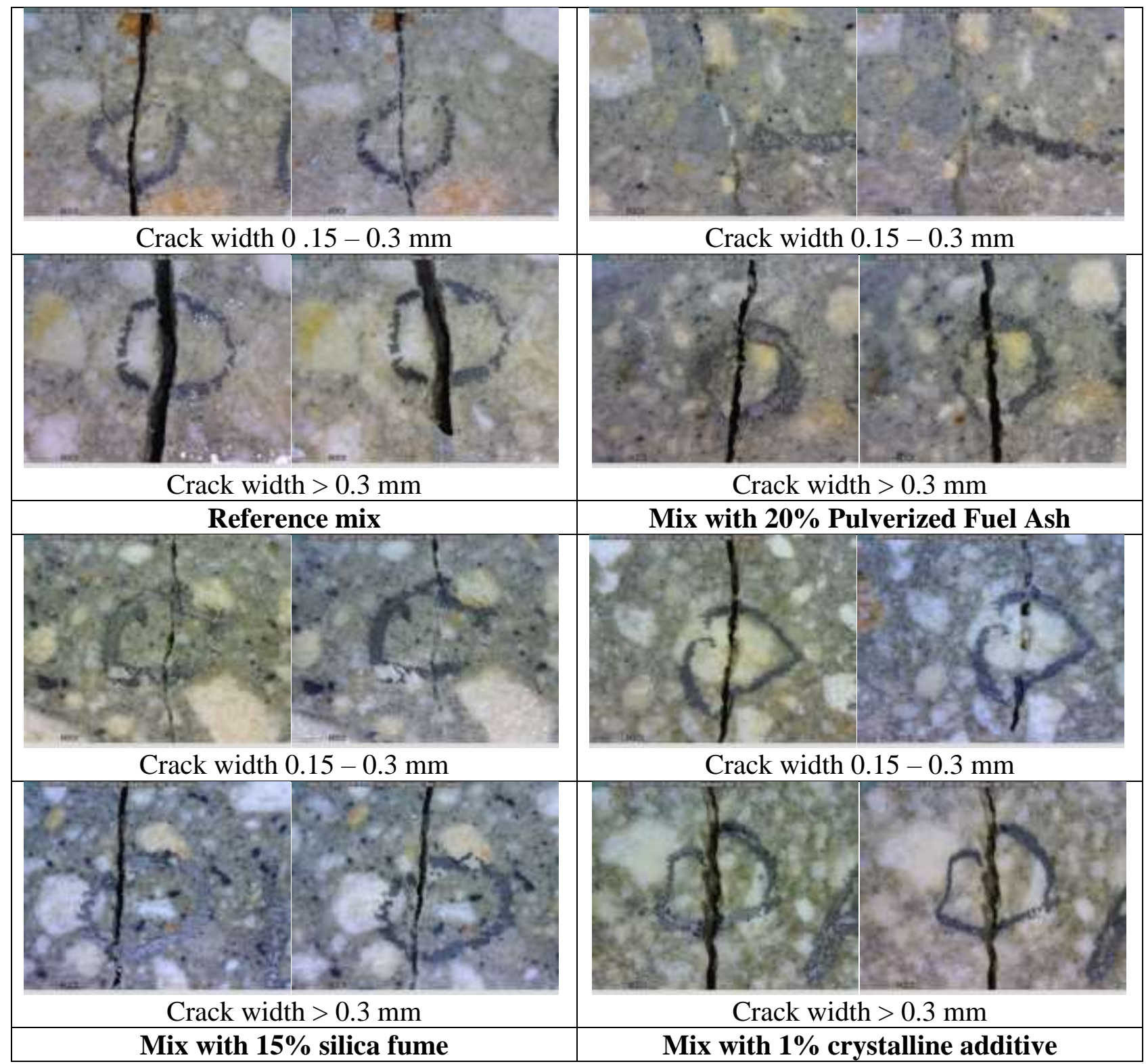

Figure 9: visual images of crack sealing after 3 months exposure to wet and dry cycles in distilled water. 


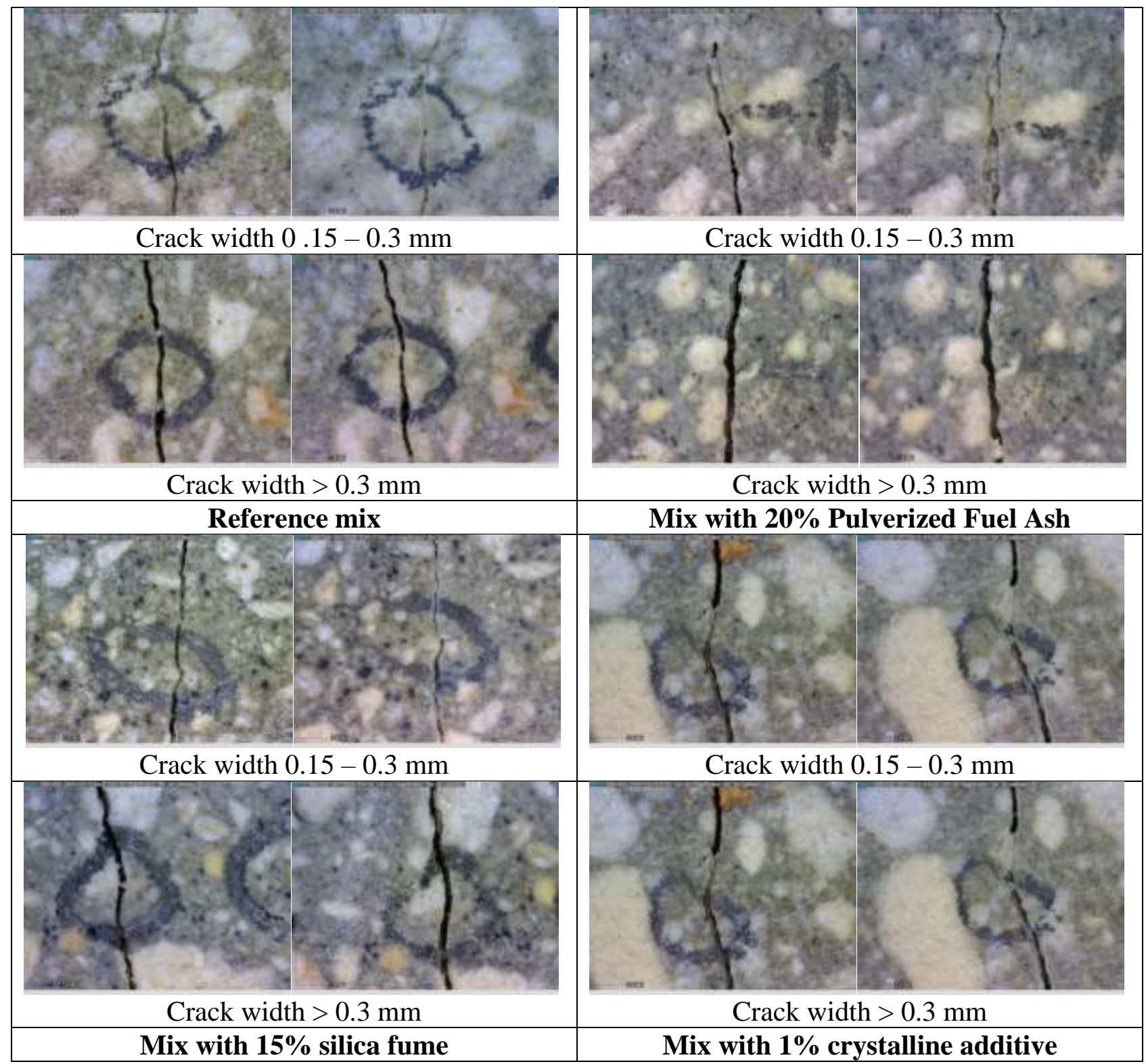

Figure 10: visual images of crack sealing after 3 months exposure to wet and dry cycles in $33 \mathrm{~g} / \mathrm{l}$ sodium chloride solution. 


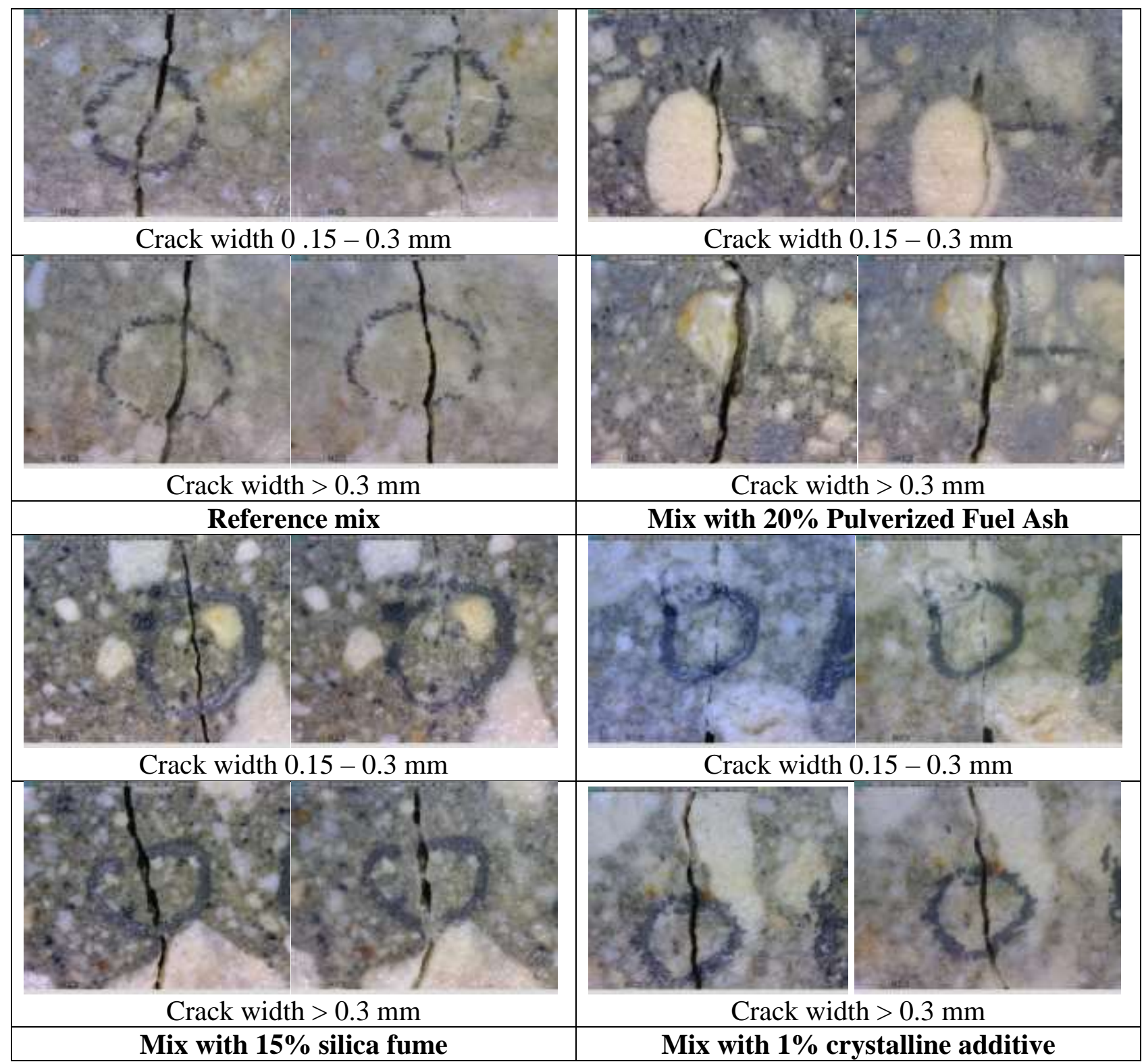

Figure 11: visual images of crack sealing after 3 months exposure to wet and dry cycles in $165 \mathrm{~g} / \mathrm{l}$ sodium chloride solution. 


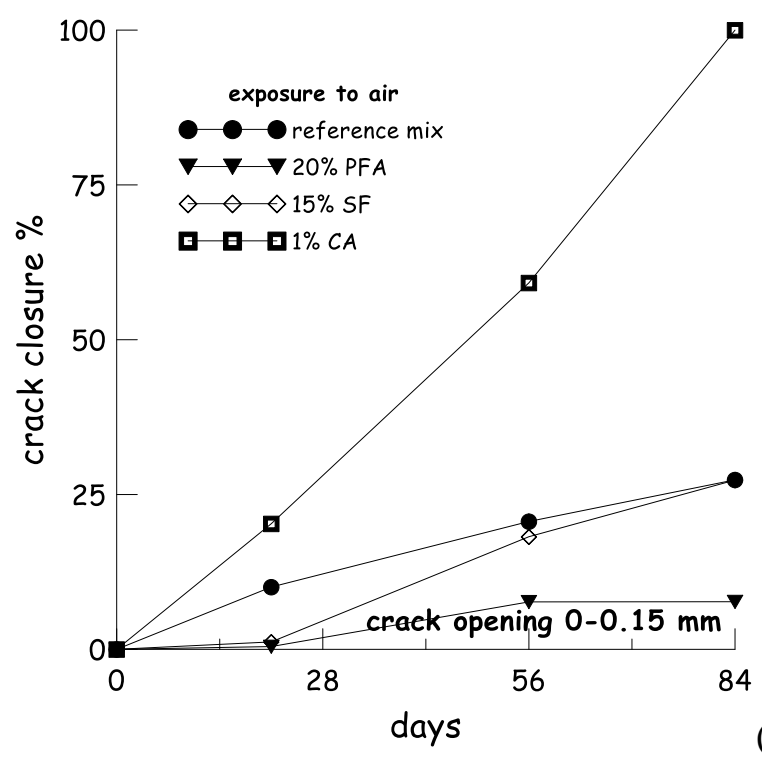

(a)

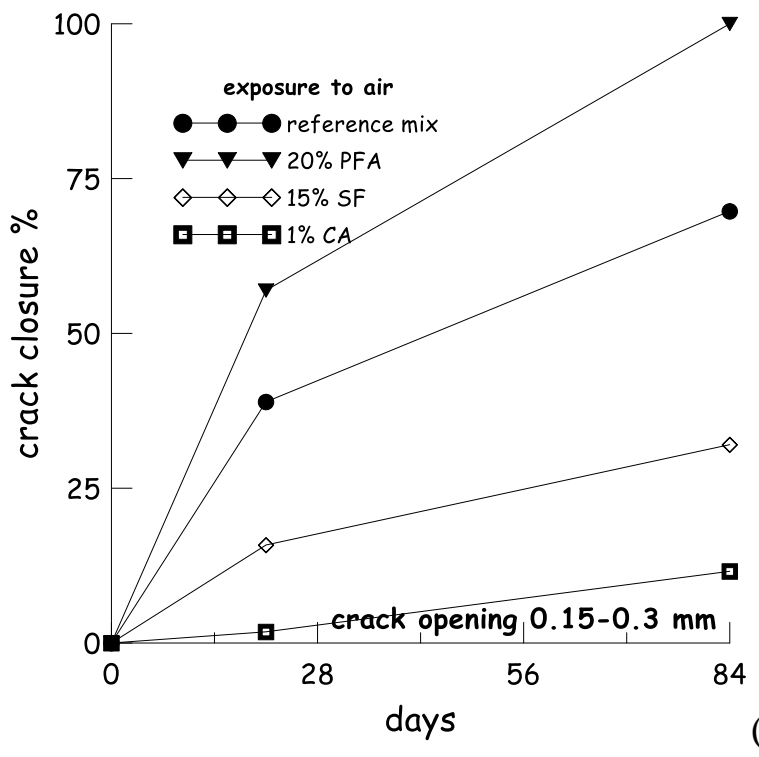

(b)

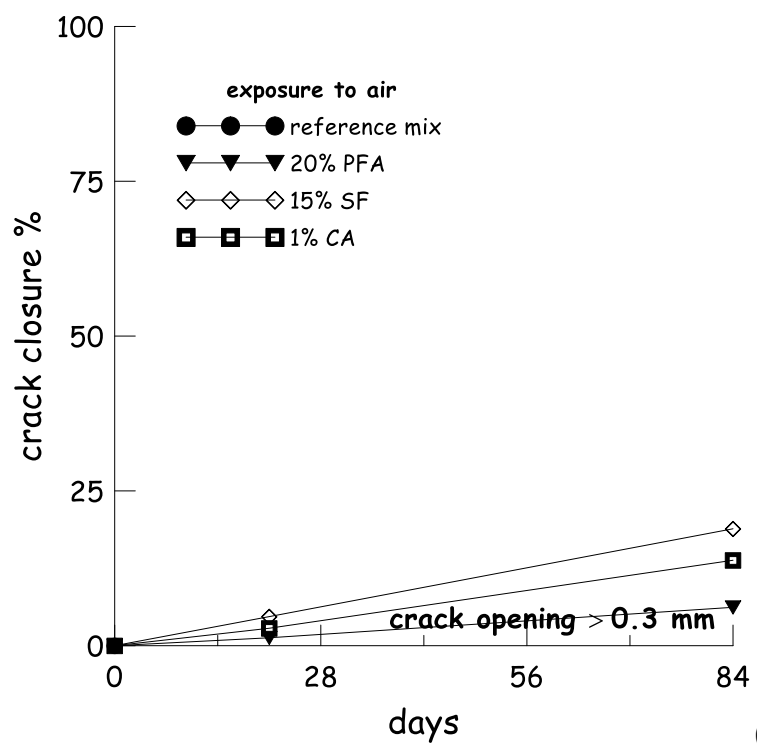

Figure 12: effects of mix composition on crack sealing under exposure to air for narrow (a), intermediate (b) and large (c) crack openings. 

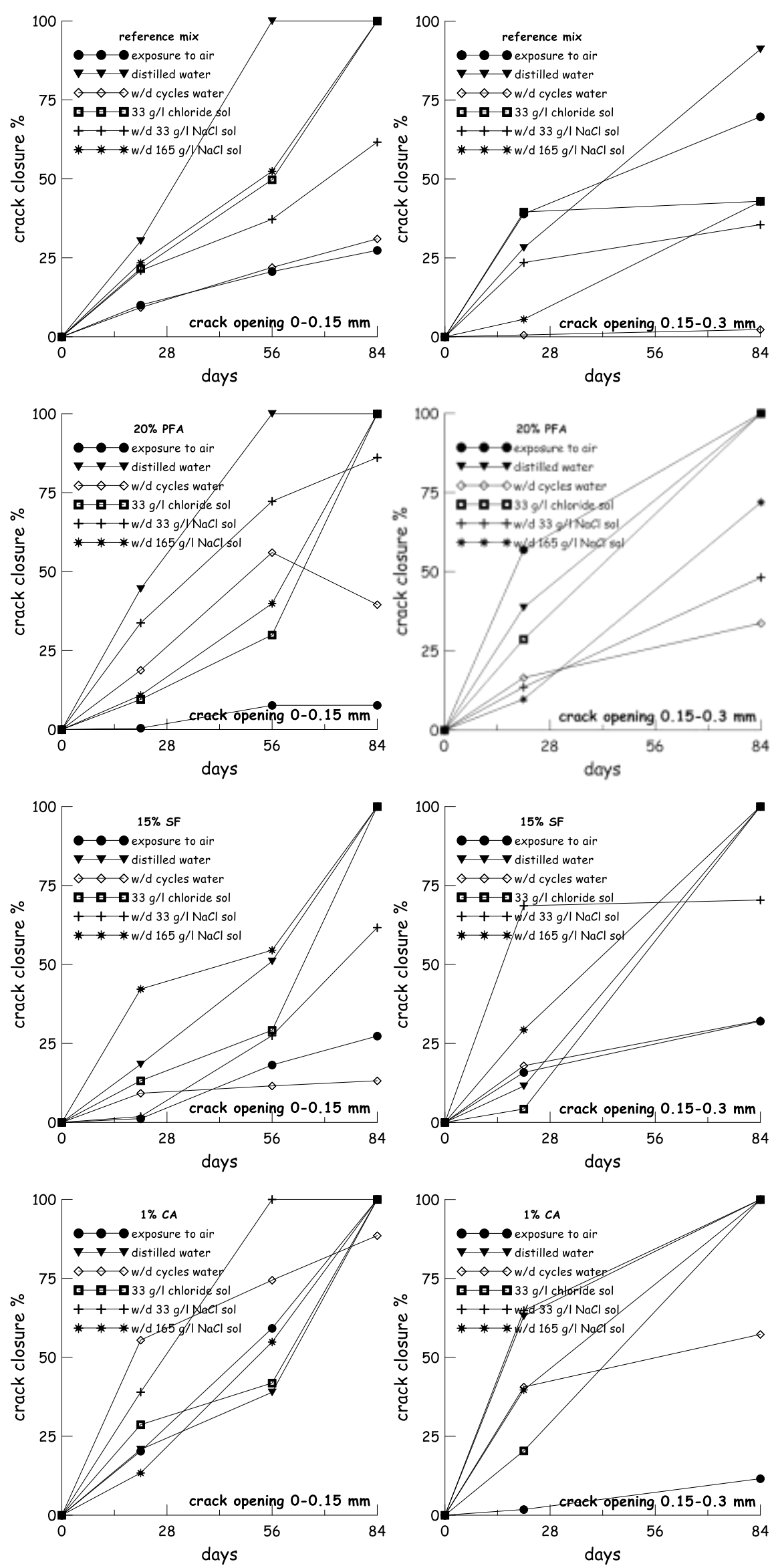

Figure 13: effects of exposure conditions on crack sealing for different investigate mixes (narrow and intermediate crack openings). 